\title{
RESENHA
}

Book Review

Revisión de libro

\section{A Universalidade do Direito à Saúde ${ }^{1}$}

The Universality of the Right to Health

La universalidad del derecho a la salud

\section{Amanda Silva Madureira ${ }^{2}$ Jaqueline Prazeres de Sena ${ }^{3}$}

O que compõe a universalidade do direito à saúde? Quais são os seus desafios diante das crescentes necessidades dos indivíduos em uma sociedade cuja concepção liberal e de escassez de recursos pode reduzir a prestação dos serviços de saúde? Essas e outras questões servem de esteio na análise acurada da autora Edith Maria Barbosa Ramos. A obra, fruto de sua tese de doutoramento junto ao Programa de Pós-Graduação em Políticas Públicas da Universidade Federal do Maranhão, traça importante percurso histórico nos textos e declarações jurídicos que proporcionaram ao direito à saúde a categoria de direito humano fundamental.

A autora demonstra a necessidade de configuração do direito à saúde como bem público global ao reconhecer que a definição de saúde da Organização Mundial da Saúde (OMS), qual seja, o completo bem-estar físico, mental e social e não apenas a ausência de doenças, em que pese não ter havido quaisquer emendas, depende de condições para o desenvolvimento das pessoas tais como, a redução da violência, a eliminação da pobreza, à redução do desemprego, à conservação do meio ambiente, dentre outras questões socioeconômicas. Nesse sentido, o leitor encontrará, além do resgate histórico dos planos legais, políticos ou institucionais, referência à história da saúde e da doença como subsídio fundamental para a compreensão de que o direito à saúde é bem, público e global.

\footnotetext{
${ }^{1}$ Barbosa Ramos EM. A Universalidade do direito à saúde. Edufma, 2014. 363 Páginas. ISBN 978-85-7862381-4.

2 Doutoranda em Políticas Públicas (UFMA). Mestre em Direito pela Universidade Federal de Santa Catarina (UFSC). Graduada em Direito pela Universidade Federal do Maranhão. Professora da Universidade CEUMA. Pesquisadora do Núcleo de Estudos em Direito Sanitário. E-mail: madureira.amanda@gmail.com.

3 Advogada, mestrado em Direito pela Universidade Federal de Minas Gerais. Professora assistente da Faculdade de Direito da Universidade Federal do Maranhão, da Faculdade Santa Terezinha-CEST e da Universidade Ceuma, pesquisadora do Núcleo de Estudos em Direito Sanitário.
} 
O primeiro capítulo aborda o conceito de direito à saúde, as instituições e políticas que tratam do direito à saúde destacando os elementos normativos que abordam o direito à saúde. Na visão da autora, a saúde global é um conceito que tem amparo em Berlinguer (1) e caracteriza a ideia de saúde com dimensões e problemas que dizem respeito a toda a humanidade uma vez que todos os povos possuem questões de saúde e doenças que os vinculam materialmente. Dessa forma, surge a globalização dos riscos de saúde, agrupando estes riscos em quatro áreas, quais sejam: o ressurgimento de antigas infecções e aparecimento de novas; as implicações para a saúde da degradação ambiental; a globalização das drogas e a violência.

Diante das teorias negadoras, ou seja, aquelas teorias que negam que se possa falar de um direito à saúde, a autora apresenta dois argumentos que demonstram a fragilidade de tal concepção. O primeiro, que tem sentido apenas conceitual falar de direito à saúde e o segundo o qual se apresenta como um direito justificado, entendendo sua justificação como metajurídica e ética, configurando-se como suficiente para resguardar um direito fundamental à proteção da saúde.

Faz-se oportuno afirmar que, diante das teorias negadoras, o direito à saúde é um direito complexo, pois expressa uma série de elementos distintos embora conectados entre si. A questão torna-se difícil quando se identifica o direito à saúde ao direito à assistência à saúde. A assistência à saúde possui caráter universal? A autora defende a tese de que o direito à saúde deve ser concebido como universal em todas as suas vertentes, inclusive na perspectiva da assistência à saúde.

O segundo capítulo tem por objetivo explicar o direito à saúde em dupla perspectiva, na ideia de recursos mínimos e na ideia de saúde mínima, bem como abordar a questão das necessidades básicas e a configuração da igualdade de oportunidades como condição para uma análise atual e concreta do direito à saúde. Por seu turno, no terceiro capítulo, a autora aborda o problema da justiça distributiva, destacando a questão da inclusão e o problema da escassez de recursos. É discutida a ideia de mercantilização e a ideia de desmercantilização do direito à saúde, bem como, determinam-se as orientações e os critérios para a tomada de decisões sobre a distribuição de recursos escassos para as política e ações de saúde.

No quarto capítulo, a autora demonstra uma preocupação com o sentido de universalização e de discriminação do direito à saúde. Parte do pressuposto de que a igualdade 
é um valor fundamental para análise das teorias sobre justiça social. No entanto, a questão deve ser posta considerando os diferentes sentidos e interseções da ideia desigualdade. capítulo ora analisado foi dividido em três tópicos: igualdade de recursos e igualdade de oportunidades; universalidade dos direitos humanos e titularidade do direito à saúde; a extensão do direito à saúde e os modelos de sistema de saúde.

A autora afirma que, mesmo considerando os diversos significados e implicações envolvendo a ideia de igualdade, duas concepções têm se destacado - a igualdade de recursos e igualdade de oportunidades. Deve-se ressaltar, no entanto, que, não raro, as orientações configuradas na igualdade de recursos e na igualdade de oportunidades podem conduzir a consequências profundamente divergentes, demonstra-se a dificuldade de harmonização das duas orientações numa única proposta coerente.

A autora elege os posicionamentos de Grosman (2) e de Anõn (3) para suas reflexões. O posicionamento de Grosman pauta-se em duas interpretações possíveis: a) que todos os indivíduos têm direito a gozar de um nível mínimo de saúde; e b) que todos os indivíduos têm direito de exigir que o Estado reverta uma quantidade mínima de recursos na proteção da saúde de cada um. Assim sendo, o compromisso com o critério de salud mínima significaria a impossibilidade de negar a inclusão e o financiamento público de tratamentos médicos considerados caros ou ineficazes, se de alguma forma estes tratamentos pudessem permitir que uma pessoa alcançasse o nível mínimo de saúde.

No entanto, para Anón (3) quando se opta pela variante do gasto mínimo, estar-seá entendendo o direito à saúde como um direito à assistência sanitária, e quando se opta pela variante da salud mínima estar-se-á discutindo o problema do direito à saúde vinculado aos seus condicionantes sociais, com aqueles elementos sociais que determinam à saúde e nas questões necessárias a incidir para garantir a equidade na condição da saúde das pessoas.

Nessa perspectiva, a autora afirma que o enfoque mais adequado para a distribuição equitativa da atenção sanitária como dimensão do direito à saúde é aquele que se baseia igualdade de recursos, pois traz à baila dois problemas fundamentais que atormentam a questão do direito à saúde, a saber: o da inclusão e o da escassez.

Segundo a professora, diante do problema da inclusão, torna-se fundamental trazer à tona a temática da titularidade do direito à saúde, em especial, o critério da universalidade. Em outras palavras, se o direito à saúde é universal e deve ser garantido apenas aos cidadãos de um Estado ou se os residentes não cidadãos devem também ser incluídos, ou se se trata 
de um direito que somente subsidiariamente deve ser reconhecido aqueles que mais necessitem por falta de recursos econômicos.

A universalidade dos direitos humanos em relação à titularidade é uma característica formal da definição de direitos humanos, mas é também uma exigência do princípio da universalidade moral, posto que não seria justificável que uma pessoa fosse titular de um direito humano e outra pertencente a mesma classe não fosse considerada também como titular.

A autora, portanto, parte do entendimento de que os direitos sociais, como qualquer outro direito humano, são universais, inclusive em relação a seus titulares. Em certos casos, talvez na maior parte, a universalidade em relação à titularidade se estenda, sem maiores restrições, a todos os seres humanos. Em outros, a universalidade em relação à titularidade alcance a um grupo específico, mas independente destas considerações os direitos sociais são sempre universais em relação aos seus titulares, mesmo quando adota-se o conceito mais comum de universalidade.

De outra parte, entende que os direitos humanos enquanto direitos fundamentais possuem uma dimensão subjetiva e uma dimensão objetiva. Nesta perspectiva, percebe que o elemento prestacional é parte da dimensão subjetiva do direito, mas a dimensão objetiva dos direitos fundamentais supõe uma obrigação do Estado com determinados valores e com a promoção das condições necessárias para que estes direitos possam ser efetivados. Um Estado no qual um grupo significativo de pessoas se encontre impossibilitado de realizar necessidades básicas demonstra a fragilidade dos direitos naquele espaço.

Não interessa que o responsável possa ser identificado ou se a fragilidade se configura como estrutural; o que ocorre é a demonstração da incapacidade do Estado em cumprir suas obrigações básicas, seja pela opção pelo modo de produção, seja pela existência de desigualdades socioeconômicas, seja pelo alto grau de exclusão social, em outras palavras, depende das prioridades que o Estado tenha eleito. Contexto este fundamental para análise das políticas de saúde nas Américas a partir de organismos internacionais com vistas ao cumprimento dos Objetivos de Desenvolvimento do Milênio (ODM) e da Agenda de Saúde para a Região das Américas (2008-2017).

No último capítulo, ocupa-se a autora do estudo das políticas de saúde nas Américas a partir dos organismos internacionais, dando ênfase aos limites e às possibilidades dos Objetivos de Desenvolvimento do Milênio e da Agenda de Saúde para Região das Américas 2008-2007. Assim, para identificar as prioridades definidas pelos Estados Americanos na 
temática da saúde, tornou-se imprescindível desenvolver uma compreensão sobre o sistema das Nações Unidas e sobre a definição das diretrizes de saúde para a política sanitária mundial.

Neste trabalho, a autora, considera sujeito de Direito Internacional Público apenas os Estados Soberanos e as Organizações Internacionais reconhecidas pela comunidade internacional. As organizações internacionais reproduzem, em parte, o jogo político que domina a ordem mundial, mas não podem ser entendidos apenas como órgãos de sustentação de uma certa ordem mundial ou mero reflexo dos interesses econômicos e políticos de determinados governos hegemônicos. Assim, para que fosse possível compreender a construção das diretrizes das políticas de saúde para o mundo e, notadamente, para a Região das Américas, tornou-se fundamental conhecer a estrutura e o funcionamento da Organização das Nações Unidas (ONU) e de suas organizações especializadas, sejam aquelas que se caracterizam pela cooperação em âmbito social, assim, como aquelas de âmbito econômico.

No texto, a ONU desponta como a principal organização internacional, encarregada de trabalhar com questões que abordam desde o desenvolvimento sustentável, o meio ambiente, a proteção dos refugiados, socorro no caso de desastre, a luta contra o terrorismo, o desarmamento, a promoção da democracia, os direitos humanos, a igualdade de gêneros, o desenvolvimento econômico e social, a remoção de minas terrestres, a expansão da produção de alimentos até à saúde internacional. Nesse último caso, deve-se destacar, ainda, a atuação da OMS e da Organização Pan-Americana de Saúde (OPAS), como principais referências para a consecução dos ODM na temática da saúde (4) (5).

Sem dúvida alguma, uma pesquisa sobre as concepções de direito à saúde que articulem os princípios da igualdade e da universalidade (numa perspectiva que contemple a ideia de bem público global) no âmbito da definição das diretrizes políticas sanitárias para a Região das Américas trouxe contribuições no que se refere à problematização de um tema de abrangência internacional, que se insere na própria constituição da conjuntura normativa mundial ao aprofundar a discussão teórica sobre os organismos internacionais e as determinações, resultado de acordos entre os Estados-Membros, que ainda se apresenta incipiente no âmbito jurídico acadêmico, mas que envolve evidente atuação de diversos setores nacionais e internacionais da arena dos direitos humanos, e notadamente, de direitos sociais. Soma-se tudo isso ao esforço da busca pela compreensão de como as políticas de saúde para a Região das Américas, políticas que foram forjadas no ambiente das organizações 
multilaterais, no seio de um modelo pluridimensional, com predomínio político dos países economicamente desenvolvidos.

Por fim, considerando as conclusões apresentadas pela autora, destaca-se a importância desse trabalho no sentido de que toda essa análise conduziu à abordagem dos problemas vinculados aos determinantes sociais da saúde que afetam com mais intensidade a vida das pessoas do que a própria distribuição da atenção médica.

Diante das questões apresentadas, foi fundamental abordar os organismos e mecanismos internacionais de declaração e proteção do direito à saúde, identificando os agentes, as racionalidades e os interesses que traçaram as diretrizes internacionais das políticas de saúde. Foram colocadas, em destaque, a condução das políticas internacionais como determinantes inquestionáveis para os Estados nacionais da região das Américas, que não raro, foram obrigados a constituírem sistemas de promoção, proteção e recuperação da saúde, vinculados e submetidos às sistemáticas delineados pelos organismos internacionais. Assim, para a autora, tornou-se imprescindível a identificação das razões técnicas, e fundamentalmente, das razões políticas, que subsidiaram os organismos internacionais na constituição das diretrizes que deveriam ser observadas pelos governos nacionais, destacando, para tanto, a conotação econômica desses subsídios.

A autora critica a construção de um modelo padrão de política de saúde para os países, notadamente, para os países em desenvolvimento. Ressalta que as diretrizes configuradas pelas agências internacionais se distanciam da realidade concreta dos países, que possuem diferentes necessidades, evidencia, ainda, que os compromissos firmados internacionalmente são extremamente frágeis, principalmente, em virtude de se tornarem, não raro, apenas políticas de governo e dificilmente serem convertidas em reais políticas de Estado. Destaca, por fim, que apesar das estratégias e das metas mínimas serem elaboradas por técnicos altamente qualificados, estão, via de regra, imensamente distantes do debate político que permite a participação efetiva dos países em desenvolvimento.

Por fim, a autora, entende que a realização do direito à saúde, e de todos os direitos humanos, requer políticas, planejamento e recursos adequados. Conclui que os ODM e a Agenda de Saúde para Região da América constituíram-se como instrumentos importantes para a compreensão dos atores, interesses e racionalidades que marcaram o processo de configuração das políticas públicas de saúde nos primeiros 15 anos do século XXI. E devem servir como pressuposto para a formulação de novas diretrizes, para as políticas de saúde no 
mundo, que garantam, de forma mais equitativas e justas, o acesso ao direito à saúde, especialmente, à população mais pobre dos países em desenvolvimento.

\section{Referências}

1 - Berlinguer G. Bioética cotidiana. México: Siglo XXI, 2002.

2 - GROSMAN, Lucas. Escasez e igualdad: los derechos sociales en la constitución. Bueno Aires: Libraria, 2008.

3 - Añón LC. Salud, justicia, derechos: el derecho a la salud como derecho social. Madrid: Dykinson, 2009.

4 - Organização Mundial da Saúde (OMS). Objetivos do desenvolvimento do milênio. 2012. [Acesso em 20 jun 2012]. Disponível em: http://www.pnud.org.br/odm.aspx

5 - Organização Pan-Americana da Saúde (OPAS). Agenda de Salud para las Américas 2008-2017. Washington, D.C.: OPAS, 2007. [Acesso em 05 jun 2011]. Disponível em: http://www1.paho.org/hg/dmdocuments/2009/Agenda Salud para las Americas 20082017.pdf 